\title{
Влияние модификации изотактического полипропилена на его транспортные свойства
}

\author{
(C) 2020 Струсовская Н.Л., Матушкина Н.Н. \\ Московский государственный университет имени М.В. Ломоносова, Москва
}

Поступила в редакцию 30.01.2020 г.

DOI: $10.17308 /$ sorpchrom.2020.20/2870

Модификацией промышленных полимеров можно создать материалы с определенным набором эксплуатационных свойств. В данной работе проведена модификация структуры пленок изотактического полипропилена марки 01030 (ПП) путем обработки их жидкими алканами с увеличивающимся числом атомов углерода (гексан, гептан, н-нонан), которая приводит к увеличению сорбции и проницаемости воды в процессе первапорации. Эксперименты проводили по четырем маршрутам, как при изучении набухания ПП, так и при первапорации.

Показано, что при проведении эксперимента по маршруту № 1 с увеличением числа атомов углерода в молекуле алкана степень набухания ПП растет, а величина плотности первапорационного потока падает. При модификации пленок ПП алканами по маршрутам №№ 3-4 происходит рост подвижности сегментов макромолекулярных цепей и увеличение расстояний между ними. При десорбции алканов образовавшаяся структура, по-видимому, сохраняется. После полного удаления ранее растворенного вещества (гексан и гептан) остаются «пустоты», через которые проникает вода (маршрут № 3) и наблюдается рост равновесной степени набухания ПП, а н-нонан полностью не удаляется, поэтому вода не может проникнуть в ПП. Аналогичное поведение наблюдается и при первапорации воды по маршруту №3. В случае маршрута № 4, когда десорбцию алканов не проводили, вода выталкивает алканы из полимера и проникает вслед за ними в пленку по образовавшимся каналам.

С повышением температуры в изучаемом интервале плотность потока алканов возрастает (для гексана в 5 раз). Увеличение плотности потока воды после модификации происходит для всех изучаемых алканов, но она уменьшается при переходе от гексана к н-нонану. Показано, что в маршруте № 2 происходит поверхностная модификация пленки, в маршрутах № 3 и № 4 - объемная модификация. Таким образом, модификация полимерных пленок с использованием гидрофобных веществ приводит к увеличению сорбции и проницаемости гидрофильных веществ (воды).

Ключевые слова: модификация, сорбция, проницаемость, первапорация, полипропилен, алканы.

\section{Введение}

Большое количество публикаций посвящено модификации промышленных полимеров с целью создания материалов с определенным набором эксплуатационных свойств, так как химическая и надмолекулярная структура, полученная в процессе синтеза, может быть несовершенна (неоднородность строения самих макромолекул, на концах макромолекул, как правило, имеются группы, отличающиеся по химическому составу от мономерных звеньев, остатки инициатора, катализатора; конфигурационная неоднородность макромолекул, стереоизомерия и т.п.) [1-5]. Авторы [1] делают вывод о том, что именно модификация полимеров предоставляет такую возможность, порой лучше, чем синтез нового соединения. В работе [1] рассмотрены различные способы физической и химической модификации полимерных материалов. Для направленного регулирования отдельных свойств необходимо зна- 
ние специфики процессов, в частности для улучшения транспортных свойств полимерных мембран при первапорации необходимо представлять, как в них проходят стадии сорбции, диффузии и десорбции веществ.

Известно, что механизм сорбционного процесса имеет сложный характер, при этом влияние на него оказывают как структура и свойства полимера и исследуемых веществ, так и взаимодействия между ними [6]. На примере алифатических и ароматических полиамидов ранее нами было показано [7], что можно существенно увеличить сорбцию гидрофильного вещества и, соответственно, проницаемость слабо сорбируемого вещества (гидрофобного) за счет использования дополнительных адсорбционных центров, возникающих при модификации полимерных пленок путем проведения сорбционных и первапорационных экспериментов по различным маршрутам. В этой работе была поставлена обратная задача: изучить сорбцию и проницаемость гидрофильных веществ (в данном случае воды) на гидрофобном материале.

Как мы писали ранее [8], изучение свойств полипропилена (ПП) нам представляется важной задачей, т. к. он обладает более сложной молекулярной структурой, чем большинство производимых промышленностью полимеров (например, полиэтилена). Для него, помимо химического состава мономера, чрезвычайно важна конфигурация цепи. Степень кристалличности влияет не только на процесс транспорта в мембране, но и на ее химические и механические свойства.

Было показано [8], что при взаимодействии ПП с водой его масса уменьшалась. Такое поведение может быть связано с наличием гидрофильных примесей в ПП, макромолекулы которого, неполярны [9].

Целью данной работы является модификация структуры ПП пленок путем обработки их жидкими алканами с увеличивающимся числом атомов углерода и выявление их влияния на массоперенос в мембранах из промышленного ПП при первапорации.

\section{Экспериментальная часть}

Объектами исследования были промышленные пленки полипропилена марки 01030 (ГОСТ 26996-86) с толщиной 20 мкм, степенью кристалличности 47.9 \% [10] и следующие сорбаты: вода, гексан, гептан, н-нонан. Их характеристики представлены в табл. 1.

Таблица 1. Характеристики объектов исследования

\begin{tabular}{|c|c|c|c|c|c|c|}
\hline Вещество & $\begin{array}{c}\delta_{\mathrm{p}} \\
\left(\mathrm{M} Д \% / \mathrm{M}^{3}\right)^{1 / 2}\end{array}$ & $\begin{array}{l}\text { Дипольный } \\
\text { момент, D }\end{array}$ & $\begin{array}{l}\text { Мол. } \\
\text { масса }\end{array}$ & $\rho, \Gamma / \mathrm{cm}^{3}$ & $\mathrm{~T}_{\text {кип }},{ }^{\circ} \mathrm{C}$ & $\begin{array}{c}\text { Динамическая } \\
\text { вязкость, сП }\end{array}$ \\
\hline ПП & $\begin{array}{c}18.8-19.2 \\
{[12]}\end{array}$ & 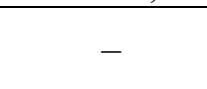 & $\begin{array}{c}200000- \\
300000\end{array}$ & $0.90-0.92$ & - & \\
\hline Вода & 49.3 & 1.84 [11] & 18 & 1.00 & 100.0 & $1.0[13]$ \\
\hline Гексан & 14.8 & 0.08 [11] & 86 & 0.65 & 68.7 & 0.3 [14] \\
\hline Гептан & 15.1 & $0[11]$ & 100 & 0.68 & 98.4 & 0.4 [14] \\
\hline н-Нонан & 15.7 [15] & 0 [11] & 128 & 0.72 & 150.8 & 0.7 [14] \\
\hline
\end{tabular}

В работах $[16,17]$ установлено, что степень набухания полимера $\left(\alpha_{\infty}\right)$ зависит от сорбционной предыстории процесса, поэтому нами были разработаны 4 маршрута проведения эксперимента, методика которых там подробно описана. Суть же их сводится к тому, что по маршруту №1 происходит обычное набухание полимера в сорбате 1 (рис. 1); по маршруту № 2 пленку, набухшую в сорбате 1, высушивают на воздухе и вновь изучают набухание в сорбате 1 . Степень набухания определяли от- 
носительно веса исходной пленки). Маршрут № 3 отличается от маршрута № 2 тем, что повторное набухание происходит в сорбате 2. Степень набухания в сорбате 2 определяли относительно веса высохшей после набухания в первом сорбате пленке. Маршрут № 4: сорбция второго сорбата на набухшей в первом сорбате пленке (рис. 3б). Степень набухания во сорбате 2 определяли относительно веса исходной пленки. Эксперимент проводили при температуре $22^{\circ} \mathrm{C}$.

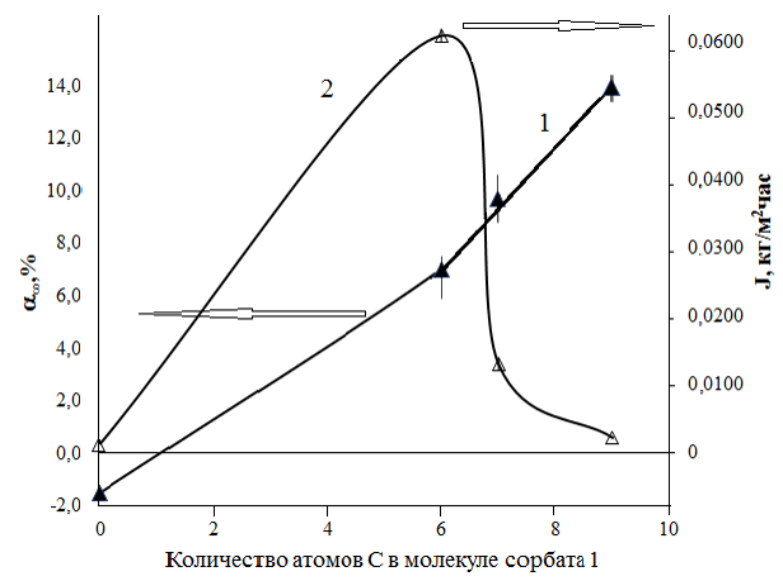

Рис. 1. Зависимость равновесной степени набухания ПП (кривая 1) и первапорационного потока через него (кривая 2) воды и алканов в зависимости от количества атомов углерода в их молекулах.

Изучение температурной зависимости проницаемости пленок ПП проводили

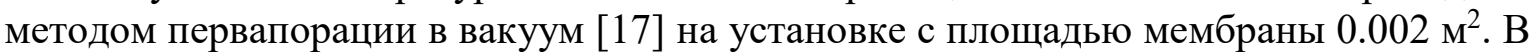
этом процессе прошедшие через мембрану пары конденсировались в ловушке, охлаждаемой жидким азотом. Для расчета плотности потока определяли массу сконденсированного вещества.

Для всех экспериментов количество параллельных опытов было не меньше пяти. Полученные результаты обрабатывали по теории ошибок. Доверительный интервал рассчитывали для уровня значимости 0.05 .

Для изучения влияния сорбционной предыстории на процесс первапорации были реализованы следующие маршруты проведения эксперимента, которые были согласованы с сорбционными методиками. Маршрут № 1 - первапорация сорбатов 1 через исходную (сухую) пленку, маршрут № 2 - первапорация воды после достижения стационарного потока сорбата 1 по маршруту 1, маршрут № 3 - первапорация воды после набухания пленки в сорбате 1 в чашке Петри до постоянного веса и сушки в первапорационной установке для предотвращения усадки пленки; маршрут № 4 аналогичен предыдущему маршруту, но сушку пленки не производили.

\section{Обсуждение результатов}

Вода и н-нонан - сорбаты с наибольшим различием свойств, определяющих величину степени набухания пленок гидрофобного изотактического ПП. Остальные сорбаты располагаются по степени набухания в них ПП в ожидаемом порядке: с увеличением числа звеньев в цепочке возрастают силы межмолекулярного взаимодействия с полимером, следовательно, возрастает и степень его набухания (см. рис. 1, кривая 1). Угол смачивания ПП водой 84 град [18] свидетельствует о наличии небольшого числа гидрофильных центров на поверхности полимера. Возможно также наличие гидрофильных примесей в объеме полимера, которые остались в нем после синтеза. По всей видимости, именно их присутствием объясняется потеря массы ис- 
ходного ПП при контакте с водой, о которой говорилось выше. Но представленные на рис. 1 (кривая 2) данные показывают, что с увеличением числа атомов углерода величина плотности первапорационного потока падает. Это происходит потому, что в данном ряду увеличиваются молекулярная масса, плотность, вязкость, т. е. не всегда близкие параметры растворимости полимера и растворителя обеспечивают высокую проницаемость последнего.

После того, как прошли стадии сорбция-десорбция-сорбция (маршрут №2, табл. 2), т. е. в предварительном сорбционном цикле примеси были вымыты, структура ПП изменилась, величины степени набухания либо остались прежними (гексан), либо стали больше. Что касается воды, то видно отсутствие гидрофильных сорбционных центров в ПП после первой стадии процесса: сорбция воды практически нулевая.

Таблица 2. Равновесная степень набухания ПП в выбранных сорбатах по маршруту №2

\begin{tabular}{|c|c|c|c|}
\hline Сорбат 1 & Сорбат 2 & Десорбция до постоянной массы, \% & $\alpha_{\infty}$, масс. \% \\
\hline Гексан & - & $-0.2 \pm 0.8$ & $6.7 \pm 0.8$ \\
\hline Гептан & - & $1.5 \pm 0.9$ & $11.7 \pm 0.7$ \\
\hline н-Нонан & - & $4.6 \pm 0.8$ & $18.0 \pm 1.0$ \\
\hline- & Вода & $-0.4 \pm 0.7$ & $0.5 \pm 0.4$ \\
\hline
\end{tabular}

При высушивании ПП пленки до постоянного веса после набухания в алканах наблюдаем следующее: гексан улетает полностью, гептана остается в пленке $1.5 \pm 0.9$ вес. \% и н-нонана $4.6 \pm 0.8$ вес. \%.

При набухании полимера проходят два процесса: диффузия вещества внутрь и релаксация объема к равновесному состоянию [19]. В результате высокого поглощения сорбата 1 и облегчения подвижности макромолекул увеличиваются межцепные расстояния в ПП. При последующей десорбции алканов образовавшаяся структура, по-видимому, сохраняется. При полном удалении ранее растворенного вещества (гексан и гептан) остаются «пустоты», через которые оказывается возможной проникновение воды: по маршруту № 3 (рис. 2а, кривая 1). В то же время н-нонан полностью не удаляется, поэтому вода не может проникнуть в ПП. Аналогичное поведение наблюдается и при первапорации воды по маршруту №3 (рис. 2а, кривая 2).
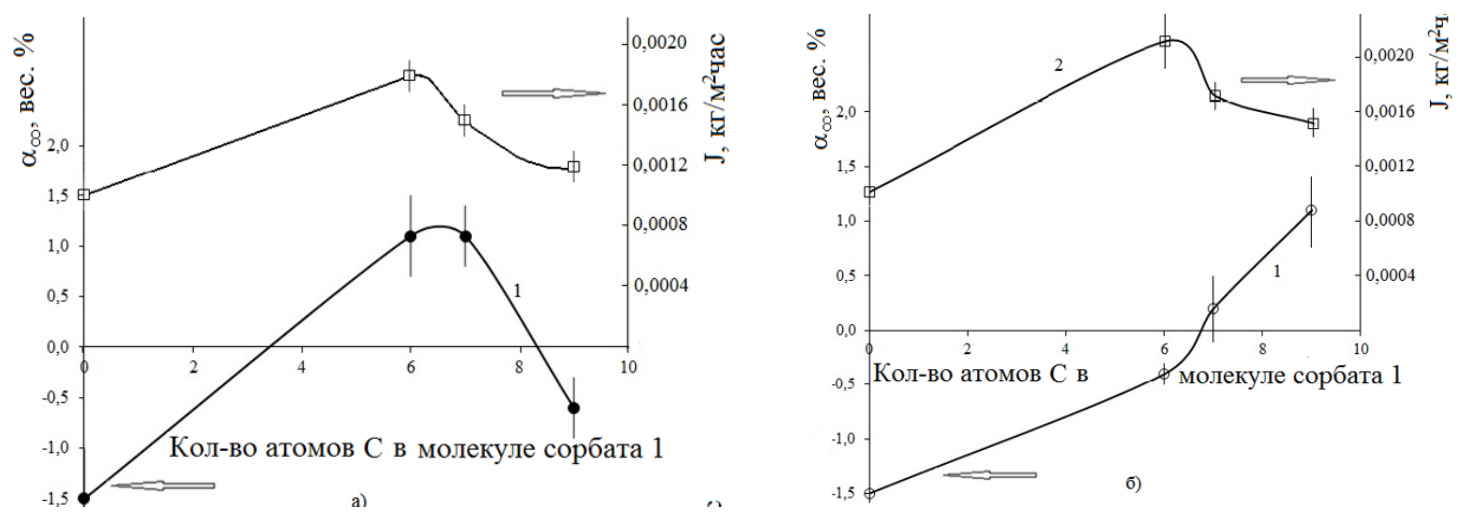

Рис. 2. Изменение свойств ПП пленки по отношению к воде при модификации ее по маршрутам №3 (рис. 2а) и № 4 (рис. 2б) алканами с увеличивающимся числом атомов углерода в молекуле. Кривые 1 - величина равновесной степени набухания

ПП в воде $\left(\alpha_{\infty}\right.$, вес. $\left.\%\right)$, кривые 2 - величина первапорационного потока воды

$$
\text { (J, кГ/м²час). }
$$


Плотность алканов увеличивается с ростом числа атомов углерода (см. табл.1), но остается меньше, чем у воды. В случае маршрута № 4 (рис. 2б) более тяжелая вода выталкивает алканы и проникает вслед за ними в пленку по образовавшимся каналам, причем тем в больших количествах, чем больше молекула первого сорбата. Это видно и по кривой 1 рис. 2б, которой соответствует кривая проницаемости (рис. 2б, кривая 2).

На рис. 3 показано влияние различных маршрутов проведения эксперимента на температурную зависимость плотности первапорационного потока воды.

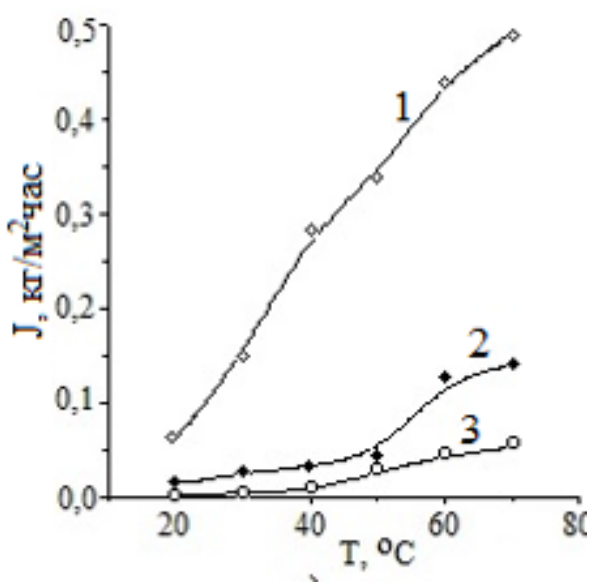

$\mathrm{a}$

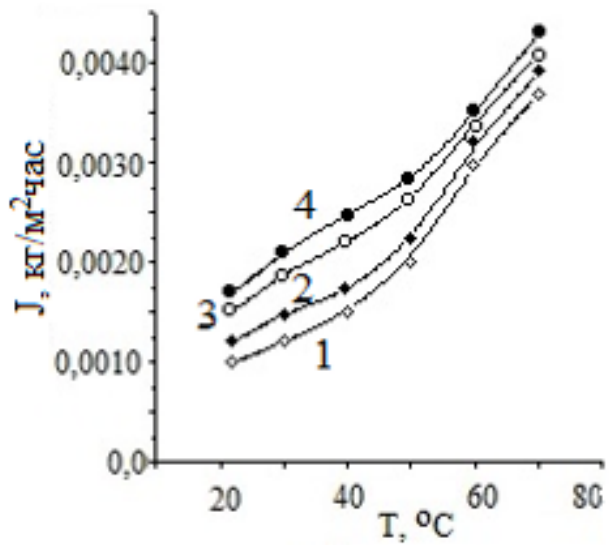

B

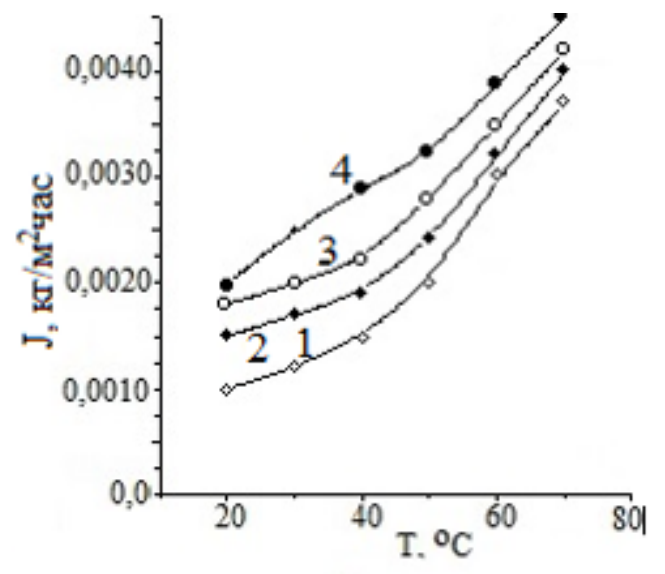

6

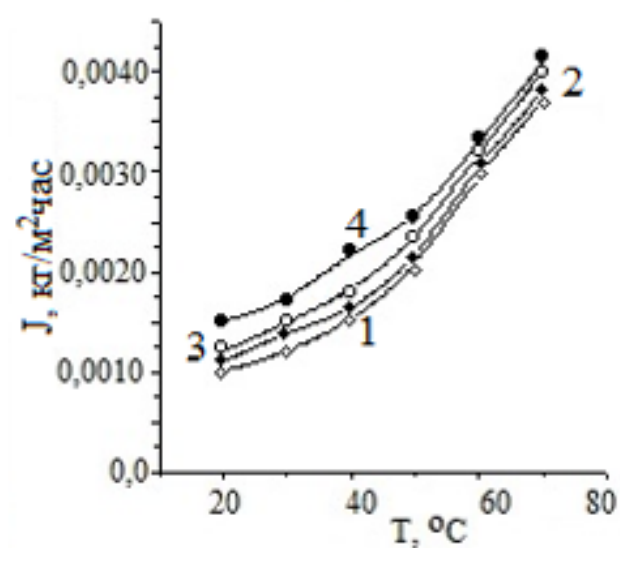

$\Gamma$

Рис. 3. Температурная зависимость плотности первапорационного потока индивидуальных веществ (a): 1- гексан, 2 - гептан, 3 - н-нонан и воды (б-г) после сорбции гексана (б), гептана (в), н-нонана (г) через мембраны из ПП в зависимости от способа модификации: 1- маршрут № 1,2 - маршрут № 2, 3 - маршрут № 3, 4 - маршрут № 4.

Данные рис. За показывают, что с увеличением температуры плотность потока исследуемых алканов возрастает, причем для гексана с повышением температуры величина плотности потока увеличивается в 5 раз в изученном интервале температур. При переходе от гексана к н-нонану величина плотности потока уменьшается по указанным выше причинам. В маршруте № 2, когда модификация осуществляется в первапорационной установке, алканы, сорбируются на стороне пленки, которая обращена к жидкости. Структура полимера изменяется не по всей толщине мембраны, т.к. в процессе первапорации прошедшее вещество находится в паровой фазе. Происходит поверхностная модификация пленки [18], снижение поверхностной энергии и увеличение потока воды через пленку. В маршрутах № 3 и № 4 происходит изме- 
нение структуры по всей толщине пленки, т.е. объемная модификация [18]: увеличивается свободный объем полимера, возрастает плотность потока воды. После высушивания пленки в установке (маршрут № 3) плотность потока становится меньше, т.к. с одной стороны, жесткое закрепление мембраны в установке препятствует ее усадке и изменению надмолекулярной структуры, а с другой, полимер в механически напряженном состоянии обладает меньшей проницаемостью [20].

Увеличение плотности потока воды после модификации происходит для всех изучаемых алканов (рис. 3, б, в, г), величина плотности потока уменьшается при переходе от гексана к н-нонану. Следует отметить, что влияние маршрута модификации наиболее ярко выражено для гексана и менее заметно для н-нонана, что связано со свойствами данных алканов.

Таким образом, модификация пленок ПП с использованием гидрофобных веществ может приводить к увеличению сорбции и проницаемости гидрофильной воды, аналогично тому, что происходило с полиамидами.

\section{Список литературы}

1. Тимакова К.А., Тарасов А.В., Федотов Ю.А., Лепешин С.А. и др. // Мембраны и мембранные технологии. 2012. Т. 2. № 2. C.74-84

2. Любимов А.Г., Прокопчук Н.Р., Мануленко А.Ф. // Химия и технология органических веществ, материалов и изделий. Труды БГТУ. 2011. № 4. С. 59-63

3. Кочнев А.М., Галибеев С.С. Модификация полимеров. Казань, Казан. гос. технол. ун-т. 2008. 533 с.

4. Назаров В.Г. Поверхностная модификация полимеров. М. МГУП. 2008. 474 с.

5. Третинников О.Н., Пилипенко В.В., Приходченко Л.К. Патент РФ, № 20111378, 2011.

6. Крижановская О.О., Синяева Л.А., Карпов С.И., Селеменев В.Ф. и др. // Сорбиионные и хроматографические прочессы. 2014. T. 14. № 5. C. 784-794

7. Струсовская Н.Л., Агеев Е.П. // Сорбиионные и хроматографические проиессы. 2015. T. 15. № 5. C. 600-606.

8. Агеев Е.П., Струсовская Н.Л., Матушкина Н.Н. // Журнал физической химии. 2017. T. 91. № 6. С. 1049-1053

9. Нигматуллина А.И., Вольфсон С.И., Охотина Н.А., Крылова С.В. // Вестник Казанского технологического университета. 2009. №. 6. C. 204-207

10. Смирнов А.В., Федоров Б.А., Темнов Д.Э., Фомичева Е.Е. // Наносистемы: Физика, химия, математика. 2012. Т. 3. № 2. С. 65-72
11. Справочник химика (под ред. Б.П. Никольского). Москва-Ленинград. Химия. 1962. T.1. C. 963-981.

12. Энциклопедия Полимеров. Ред. коллегия: В.А. Каргин и др. М. Советская Энциклопедия. 1972. Т. 1.1224 с.

13. Краткий справочник химика / Сост.: В.И. Перельман. Общ. ред.: Б.В. Некрасов. 3е изд. М. Госхимиздат. 1954. 560 с.

14. Переверзев А.Н., Богданов Н.Ф., Рощин Ю.Н. Производство парафинов. М. Химия. $1973.224 \mathrm{c.}$

15. Косточко А.В., Валишина 3.Т., Шипина О.Т. Прогнозирование совместимости в системе полимер-растворитель. Казань. Издательство КНИТУ. 2014. 84 с.

16. Ageev E.P., Strusovskaya N.L., Matushkina N.N. // Petroleum Chemistry. 2015. Vol. 55. No 5. pp. 401-405. DOI: $10.1134 / \mathrm{S} 0965544115050023$

17. Агеев Е.П., Матушкина Н.Н., Долгова А.А. // Сорбионные и хроматографческие nроиессы. 2011. T. 11. № 3. С. 309-315.

18. Миронюк А.В., Придатко А.В., Сиволапов П.В., Свидерский В.А. // ВосточноЕвропейский журнал передовых технологий. Технологии органических и неорганических веществ. 2014. Т. 1. № 6 (67). С. 23-26

19. Schott H. // Journal of pharmaceutical sciences. 1990. Vol. 5. No 81. pp. 467-470.

20. Агеев Е.П., Матушкина Н.Н., Вихорева Г.А., Федотов Ю.А. // Сорбиионные и хроматографические прочессы. 2006. Т. 6. № 1. C. 55-61. 


\title{
Effect of isotactic polypropylene modification on its transport properties
}

\author{
(C) 2020 Strusovskaya N.L., Matushkina N.N.
}

\author{
Moscow State University, Moscow
}

\begin{abstract}
Modification of industrial polymers can be used to create materials with a specific set of performance properties. In this study, the structure of 01030 grade isotactic polypropylene (PP) films was modified by treating them with liquid alkanes with an increasing number of carbon atoms (hexane, heptane, n-nonane), which led to an increase in the sorption and water permeability in the process of pervaporation. The experiments consisted of four tests for both PP swelling and pervaporation studies.

Test 1 of the experiment showed that with an increase in the number of carbon atoms in the alkane molecule, the degree of PP swelling increases, and the pervaporation flux density decreases. Tests 3 and 4 involving the modification of PP films by alkanes revealed an increase in the mobility of segments of macromolecular chains and the distance between them. Upon the desorption of alkanes, the formed structure is apparently preserved. As a result of the complete removal of the previously dissolved substance (hexane and heptane) there remain «voids» through which water penetrates (test 3 ) and there is an increase in the equilibrium degree of PP swelling, while n-nonane is not completely removed, so water cannot penetrate into the PP. A similar behaviour is observed in the process of pervaporation of water in test 3 . In case of test 4 , which did not involve desorption of alkanes, water «pushes» the alkanes out of the polymer and following them penetrates into the film through the formed channels.

With an increase of temperature in the studied interval, the alkane flux density increases ( 5 times for hexane). An increase in the density of the water flow after modification occurs for all the studied alkanes, however, it decreases upon the transition from hexane to n-nonane. Test 2 resulted in the modification of the film surface, whereas tests 3 and 4 led to volume modification. Thus, the modification of polymer films using hydrophobic substances leads to an increase in the sorption and permeability of hydrophilic substances (water).

Keywords: modification, sorption, permeability, pervaporation, polypropylene, alkanes.
\end{abstract}

\section{References}

1. Timakova K.A., Tarasov A.V., Fedotov Yu.A., Lepeshin S.A. et al., Membrany $i$ membrannye tekhnologii, 2012, Vol. 2, No 2, pp.74-84.

2. Lyubimov A.G., Prokopchuk N.R., Manulenko A.F., Khimiya i tekhnologiya organicheskih veshchestv, materialov i izdelij, Trudy BGTU, 2011, No 4, pp. 59-63.

3. Kochnev A.M., Galibeev S.S., Modifikaciya polimerov, Kazan', Kazan. gos. tekhnol. unt., 2008, 533 p.

4. Nazarov V.G., Poverhnostnaya modifikaciya polimerov. M., MGUP, 2008, 474 p.

5. Tretinnikov O.N., Pilipenko V.V., Prihodchenko L.K. Patent RF, No 20111378, 2011.

6. Krizhanovskaya O.O., Sinyaeva L.A., Karpov S.I., Selemenev V.F. et al., Sorbtsionnye $i$ khromatograficheskie protsessy, 2014, Vol. 14, No 5, pp. 784-794.

7. Ageev E.P., Strusovskaya N.L., Matushkina N.N., Zhurnal fizicheskoj khimii, 2017, Vol. 91, No 6, pp. 1049-1053.

8. Nigmatullina A.I., Vol'fson S.I., Ohotina N.A., Krylova S.V., Vestnik Kazanskogo tekhnologicheskogo universiteta, 2009, No 6, pp. 204-207.

9. Smirnov A.V., Fedorov B.A., Temnov D.E., Fomicheva E.E., Nanosistemy: Fizika, khimiya, matematika, 2012, Vol. 3, No 2, pp. 65-72.

10.Spravochnik himika (pod red. B.P. Nikol'skogo). Moskva-Leningrad, Khimiya, 1962, Vol. 1, pp. 963-981.

11.Enciklopediya Polimerov. Red. kollegiya: V.A. Kargin i dr. Moskva, Sovetskaya Enciklopediya, 1972, Vol. 1, 1224 p.

12.Kratkij spravochnik khimika, Sost.: V.I. Perel'man. Obshch. red.: B.V. Nekrasov. 3-e izd. M., Goskhimizdat. 1954, 560 p.

13.Pereverzev A.N., Bogdanov N.F., Roshchin Yu.N. Proizvodstvo parafinovб M, Khimiya, 1973, 224 p.

14.Kostochko A.V., Valishina Z.T., Shipina O.T. Prognoeirovanie sovmestimosti v sisteme polimer-rastvoritel'. Kazan', Izdatel'stvo KNITU, 2014, 84 p. 
15.Ageev E.P., Strusovskaya N.L., Matushkina N.N., Petroleum Chemistry, 2015, Vol. 55, No 5, pp. 401-405. DOI: $10.1134 / \mathrm{S} 0965544115050023$

16.Strusovskaya N.L., Ageev E.P. Sorbtsionnye i khromatograficheskie protsessy 2015, Vol. 15, No 5, pp. 600-606.

17.Ageev E.P., Matushkina N.N., Dolgova A.A., Sorbtsionnye $i$ khromatograficheskie protsessy, 2011, Vol. 11, No 3, pp. 309-315.

Струсовская Надежда Львовна - к.Х.н., научн. сотр., Московский государственный университет имени М.В. Ломоносова, химический факультет, кафедра физической химии, Москва

Матушкина Наталия Николаевна - к.Х.Н., ст. научн. сотр., Московский государственный университет имени М.В. Ломоносова, химический факультет, кафедра физической химии, Москва, (495) 9391087
18.Mironyuk A.V., Pridatko A.V., Sivolapov P.V., Sviderskij V.A. Vostochno-Evropejskij zhurnal peredovyh tekhnologij. Tekhnologii organicheskih i neorganicheskih veshchestv, 2014, Vol. 1, No 6 (67), pp. 23-26.

19. Schott H., Journal of pharmaceutical sciences, 1990, Vol. 5, No 81, pp. 467-470.

20.Ageev E.P., Matushkina N.N., Vihoreva G.A., Fedotov Yu.A., Sorbtsionnye i khromatograficheskie protsessy, 2006, Vol. 6, No 1, pp. 55-61.

Strusovskaya Nadezhda L. - PHD, Researcher, Moscow M.V. Lomonosov State University, Chemistry Department, Division of Physical Chemistry. Postal address: Chemistry Department, Moscow State University, Moscow, Russia

Matushkina Nataliya N. - PHD, Senior Researcher, Moscow M.V. Lomonosov State University, Chemistry Department, Division of Physical Chemistry. Postal address: Chemistry Department, Moscow State University, 119991, Moscow, Russia, e-mail: $\underline{\text { mnn@phys.chem.msu.ru }}$ 